\title{
The Role of Consolidative Radiotherapy after a Complete Response to Chemotherapy in the Treatment of Diffuse Large B-Cell Lymphoma in the Rituximab Era: Results from a Systematic Review with a Meta-Analysis
}

\author{
Chunhong Hu$^{a} \quad$ Chao Deng $^{a} \quad$ Wen Zou $^{a} \quad$ Guangsen Zhang ${ }^{b}$ Jingjing Wang ${ }^{a}$ \\ ${ }^{a}$ Department of Oncology, and ${ }^{b}$ Department of Hematology, Institute of Molecular Hematology, The Second \\ Xiangya Hospital of Central South University, Changsha, PR China
}

For editorial comment see p. 109

\section{Key Words}

Diffuse large B-cell lymphoma · Radiation · Rituximab ·

Complete response

\begin{abstract}
Background: The current standard therapy for patients with diffuse large B-cell lymphoma (DLBCL) is rituximab plus cyclophosphamide, doxorubicin, vincristine and prednisone (RCHOP). The role of radiotherapy (RT) after complete response (CR) to RCHOP in patients with DLBCL remains unclear. This systematic review with a meta-analysis is an attempt to evaluate this role. Methods: Studies that evaluated RT versus no-RT after CR to RCHOP for DLBCL patients were searched in databases. Hazard ratios (HR) with their respective $95 \%$ confidence intervals $(\mathrm{Cl})$ were calculated using a random-effects model. Results: A total of 4 qualified retrospective studies (633 patients) were included in this review. The results suggested that RT improved overall survival (OS; HR $0.33,95 \% \mathrm{Cl} 0.14-0.77$ ) and progression-free/event-free survival (PFS/EFS; HR 0.24, 95\% Cl 0.11-0.50) in all patients compared with no-RT. In a subgroup analysis of patients with stage III-IV DLBCL, RT improved PFS/EFS (HR 0.19, 95\% $\mathrm{Cl} 0.07-0.51)$ and local control (HR $0.12,95 \% \mathrm{Cl} 0.03-0.44)$,
\end{abstract}

with a trend of improving OS (HR 0.35, 95\% Cl 0.12-1.05). Conclusion: Consolidation RT could significantly improve outcomes of DLBCL patients who achieved a CR to RCHOP. However, the significance of these results was limited by these retrospective data. Further investigation of the role of consolidation RT in the rituximab era is needed.

(c) 2015 S. Karger AG, Basel

\section{Introduction}

Diffuse large B-cell lymphoma (DLBCL) is the most common subtype of non-Hodgkin lymphoma (NHL), and constitutes $30-40 \%$ of all adult NHLs [1]. The addition of rituximab has revolutionized the treatment of DLBCL. Rituximab combined with CHOP (cyclophosphamide, doxorubicin, vincristine and prednisone) chemotherapy (RCHOP) has been established as the standard treatment for patients with DLBCL. Although the majority of patients initially respond to this therapeutic approach, some relapse and eventually die from their disease. Researchers focus on supplemental treatment such as radiation therapy (RT). In the prerituximab era, several studies found a recurrence in $52-65 \%$ of patients who

\section{KARGER 125}

(c) 2015 S. Karger AG, Base

$0001-5792 / 15 / 1342-0111 \$ 39.50 / 0$

E-Mail karger@karger.com

www.karger.com/aha
Jingjing Wang

Department of Oncology, The Second Xiangya Hospital of Central South University Renmin Road 139

Changsha, Hunan 410011 (PR China)

E-Mail sky8278@aliyun.com 
had achieved an initial complete response (CR) to chemotherapy alone, while consolidation RT after CHOP chemotherapy could decrease the risk of disease recurrence and improve the outcome of patients with stage IIV DLBCL [2-5].

In the rituximab era, the addition of rituximab to CHOP has been confirmed to be effective and safe for DLBCL in multiple randomized trials [6-9], with the question being raised whether RT is still needed for DLBCL when rituximab is used. The 2013 National Comprehensive Cancer Network guidelines failed to acknowledge the role of consolidative RT as part of standard firstline therapy, although they included RT as an option. Furthermore, for DLBCL patients who achieved CR after RCHOP, these guidelines suggested that follow-up treatment should be 'observation or consolidation RT'. The role of consolidative RT in such patients is controversial. Given the lack of a randomized trial of this issue, a metaanalysis of cohort and case-control studies could serve to better characterize the role of RT and could provide some reliable assessment for clinical decision-making. The aim of our study was to evaluate the role of RT after CR to rituximab combined with CHOP for DLBCL patients.

\section{Methods}

Data Sources and Searches

Systematic computerized searches of the MEDLINE, EMBASE and The Cochrane Library databases (until March 2014) were performed. The following search terms were used: 'DLBCL', 'diffuse large B cell lymphoma', 'rituximab', 'RCHOP', 'CR', 'complete response', 'radiotherapy', 'radiation' and 'RT'. Reference lists of all recovered trials and relevant reviews were also considered. Additional searches of the American Society of Clinical Oncology (ASCO), the American Society for Therapeutic Radiology and Oncology (ASTRO), the American Society of Hematology (ASH), the European Conference on Clinical Oncology (ECCO) and the European Society of Medical Oncology (ESMO) meeting abstracts from 2000-2013 were performed. In studies with multiple publications from the same patient sample, only data from the most recent publication were included in the meta-analysis.

\section{Study Selection}

Three investigators (J.W., C.H. and C.D.) reviewed citations identified by the search strategy to generate a list of potentially relevant articles. They then reviewed the abstracts of these studies. If the applicability of a study could not be determined by title or abstract alone, the full text was reviewed. Articles were independently checked for possible inclusion, and disagreements were resolved through consensus with a fourth reviewer (G.Z.).

Studies were included for analysis if they fulfilled one of the following criteria: (1) if they were cohort or case-control studies that compared consolidative RT and observation for patients with DLBCL who achieved CR after RCHOP, (2) they reported both the number of patients with and without RT, (3) they reported overall survival (OS), progression-free survival (PFS), event-free survival (EFS) and local control [9] both in patients undergoing RT and those not undergoing RT. OS was evaluated from the date of randomization to death from any cause or censored at the time of last follow-up. PFS was defined as the time from the date of randomization until the date of disease progression or death. EFS was defined as the time from randomization until the first event, including local regional/distant failure or death. Local control (LC) was defined as the absence of disease recurrence within the initially presenting sites in both patients who did or did not receive RT, timed from the date of completion of chemotherapy, regardless of disease status outside of the field. Patients without a local recurrence were censored at death or last follow-up date.

We included articles published in English. We excluded studies that (1) included patients with refractory disease, and not achieving CR or (2) only reported outcome measures for patients undergoing RT but not for those without RT. Additional exclusion criteria included the lack of original data and incomplete reports. Full-text versions of all eligible studies were obtained for quality assessment and data extraction.

\section{Data Extraction and Quality Assessment}

Three investigators (J.W., C.H. and C.D.) independently extracted required information from eligible studies using standardized forms. A fourth reviewer (G.Z.) was available to resolve discrepancies between the two sets of extracted data. The following data were collected from each study: general identification information (author, title, journal, date of publication and duplication of publication), trial, type of patients, intervention characteristics and reported outcomes. When it was not possible to obtain data from the published trial, we tried to contact the authors to provide the information or additional data. Three investigators (J.W., C.H. and C.D.) assessed study quality by means of a modified checklist based upon the Newcastle-Ottawa scale, with discrepancies resolved by consensus. This instrument rates observational studies on a 9-point scale based on appropriateness of the study sample, comparability of study groups and adequacy of assessing exposure and outcomes [10].

\section{Data Synthesis and Statistical Analysis}

Review Manager 5.2 software was used to perform the metaanalysis. For time-to-event variables, the effect of the treatment for each individual study was expressed as a hazard ratio (HR) of RT arm over no-RT arm. The $95 \%$ confidence interval (CI) was calculated for each point estimate. The HR and 95\% CI were directly extracted from the Cox proportional hazards model used for the multivariate analysis of original papers. When it was not possible to obtain these values from the original paper, we estimated them from survival curves using the methods described by Parmar et al. [11]. Calculations were carried out using the spreadsheet provided by Tierney et al. [12]. If the HR is calculated for no-RT versus RT in the original paper ( 1 divided by this HR, i.e. $1 / \mathrm{HR}$ ), then we obtain a new HR which is calculated for RT versus no-RT. For the time-to-event variables, we performed a meta-analysis by transforming the HRs and their standard errors (SEs) into their log counterparts, applying the inverse variance method and then transforming them back into the HR scale.

HRs and their respective 95\% CIs were calculated using a DerSimonian and Laird random-effects model [13]. Statistical hetero- 
Table 1. Characteristics of studies identified for the meta-analysis

\begin{tabular}{|c|c|c|c|c|c|c|c|c|c|c|c|c|}
\hline First author & Journal & $\begin{array}{l}\text { Country } \\
\text { of origin }\end{array}$ & $\begin{array}{l}\text { Age, years } \\
\text { (median) }\end{array}$ & $\begin{array}{l}\text { Follow-up } \\
\text { duration, } \\
\text { months } \\
\text { (median) }\end{array}$ & Stage & $\begin{array}{l}\text { Patients, n } \\
\text { (RT/no-RT) }\end{array}$ & $\begin{array}{l}\mathrm{CHOP} \\
\text { regimen }\end{array}$ & $\begin{array}{l}\text { Radiation } \\
\text { dose, Gy }\end{array}$ & $\begin{array}{l}\text { Definition } \\
\text { of bulky } \\
\text { disease }\end{array}$ & $\begin{array}{l}\mathrm{OS}^{\mathrm{a}} \\
\mathrm{HR} \\
(95 \% \mathrm{CI})\end{array}$ & $\begin{array}{l}\mathrm{PFS}^{\mathrm{a}} \\
\mathrm{HR} \\
(95 \% \mathrm{CI})\end{array}$ & $\begin{array}{l}\text { EFS }^{a} \\
\text { HR } \\
(95 \% \text { CI })\end{array}$ \\
\hline Phan [16] & $\begin{array}{l}\text { J Clin } \\
\text { Oncol }\end{array}$ & USA & $\begin{array}{l}20-92 \\
(61)\end{array}$ & $\begin{array}{l}4-85 \\
(36)\end{array}$ & I-IV & $\begin{array}{l}291 \\
(84 / 207)\end{array}$ & $\begin{array}{l}\text { RCHOP* } \\
6-8\end{array}$ & $30-39.6$ & $>5 \mathrm{~cm}$ & $\begin{array}{l}0.813 \\
(0.04-16.67)\end{array}$ & $\begin{array}{l}0.52 \\
(0.087-3.125)\end{array}$ & \\
\hline $\begin{array}{l}\text { Marcheselli } \\
{[17]}\end{array}$ & $\begin{array}{l}\text { Leuk } \\
\text { Lymphoma }\end{array}$ & Italy & $\begin{array}{l}>18 \\
(69)\end{array}$ & $\begin{array}{l}1-81 \\
(30)\end{array}$ & I-IV & $\begin{array}{l}153 \\
(31 / 122)\end{array}$ & RCHOP*6 & 34 & $>6 \mathrm{~cm}$ & $\begin{array}{l}0.23 \\
(0.05-1.03)\end{array}$ & & $\begin{array}{l}0.24 \\
(0.06-0.92)\end{array}$ \\
\hline Dorth [18] & $\begin{array}{l}\text { Int J Radiat } \\
\text { Oncol Biol } \\
\text { Phys }\end{array}$ & USA & $(62)$ & $\begin{array}{l}12-204 \\
(56.4)\end{array}$ & III-IV & $\begin{array}{l}79 \\
(38 / 41)\end{array}$ & $\begin{array}{l}\mathrm{RCHOP}^{*} 6 \\
(65 \%)\end{array}$ & 25 & $7 \mathrm{~cm}$ & $\begin{array}{l}0.48 \\
(0.13-1.75)\end{array}$ & & $\begin{array}{l}0.23 \\
(0.07-0.77)\end{array}$ \\
\hline Shi [19] & $\begin{array}{l}\text { Int J Radiat } \\
\text { Oncol Biol } \\
\text { Phys }\end{array}$ & USA & $\begin{array}{l}20-81 \\
(59.4)\end{array}$ & $\begin{array}{l}1-151 \\
(32.9)\end{array}$ & III-IV & $\begin{array}{l}110 \\
(14 / 96)\end{array}$ & RCHOP*6 & 30.6 & $\geq 5 \mathrm{~cm}$ & $\begin{array}{l}0.169 \\
(0.023-1.263)\end{array}$ & $\begin{array}{l}0.098 \\
(0.013-0.733)\end{array}$ & \\
\hline
\end{tabular}

${ }^{a}$ Values are for RT/no-RT.

geneity of the results of the studies was assessed by the $\chi^{2}$ test, expressed with the $\mathrm{I}^{2}$ index, as described by Higgins et al. [14]. A $\chi^{2} \mathrm{p}$ value of $<0.05$ or $\mathrm{I}^{2}$ values $>50 \%$ were consistent with possible substantial heterogeneity. When heterogeneity was detected, a possible explanation for it was intensively pursued. If a reasonable cause was found, a separate analysis was then performed. When the cause was not apparent and heterogeneity was caused by divergent data in terms of direction of results, we chose not to pool the data. Publication bias was evaluated by means of Egger's test [15]. Analysis of sensitivity was performed to evaluate the stability of the results, namely, a single study in the meta-analysis was deleted each time to reflect the influence of the individual data set to the pooled HR.

\section{Results}

\section{Literature Search}

The literature search yielded 722 potentially relevant published titles. After the initial review, 21 titles were potentially appropriate. Of these, 13 were excluded for the following reasons: they were not original studies, they did not concern DLBCL, they did not include a no-RT group and there was no outcome of interest. After reviewing the remaining 8 studies, we excluded another which did not have a no-RT group, 2 which did not provide data on patients with RT and 1 which did not include patients treated with rituximab. Finally, 4 relevant studies, comprising a total of 633 patients, were included [16-19]. The flowchart of the reviews showed the detailed process of selection (fig. 1).

\section{Study Characteristics}

The main characteristics of the included studies are shown in table 1; all were of retrospective design. All patients were older than 18 years, and the median age was approximately 60 years. Two studies included patients

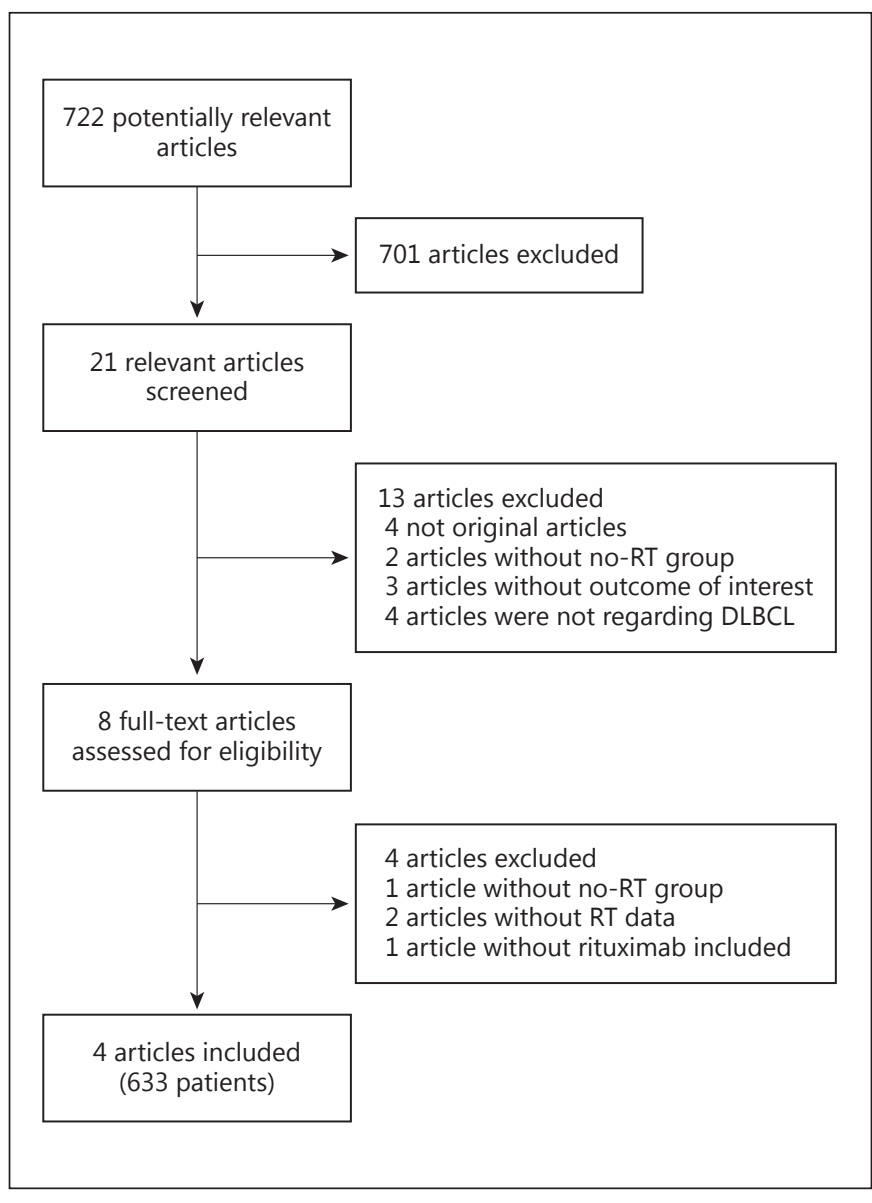

Fig. 1. Flowchart for the process of selecting eligible publications. 


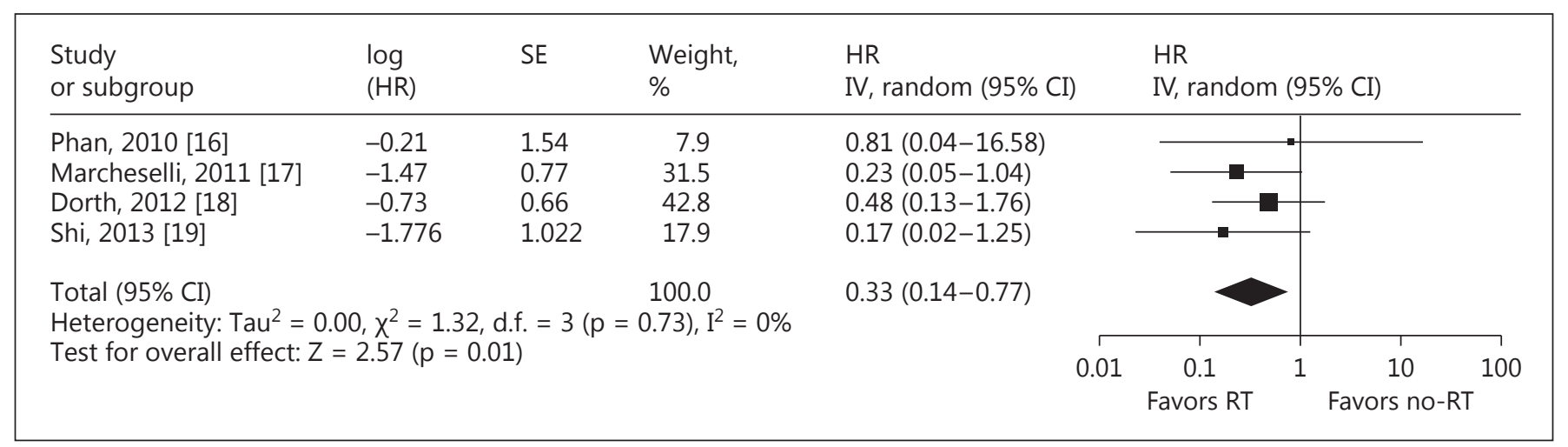

Fig. 2. Forest plot of OS for all the patients. $S E=$ Standard error.

Table 2. Quality assessment of studies

\begin{tabular}{llllllll}
\hline First author, year & $\begin{array}{l}\text { RT cohort } \\
\text { representative }\end{array}$ & $\begin{array}{l}\text { No-RT } \\
\text { cohort } \\
\text { selection }\end{array}$ & $\begin{array}{l}\text { Ascertainment } \\
\text { of exposure }\end{array}$ & $\begin{array}{l}\text { Outcome } \\
\text { not initially } \\
\text { present }\end{array}$ & $\begin{array}{l}\text { Control for } \\
\text { potential } \\
\text { confounders }\end{array}$ & $\begin{array}{l}\text { Assessment } \\
\text { of outcome }\end{array}$ & $\begin{array}{l}\text { Follow-up } \\
\text { period }\end{array}$ \\
\hline Phan, 2010 [16] & 1 & 1 & 1 & 1 & 0 & 1 & 1 \\
of cohort \\
Marcheselli, 2011 [17] & 1 & 1 & 1 & 1 & 0 & 1 & 1 \\
Dorth, 2012 [18] & 1 & 1 & 1 & 1 & 1 & 1 & 1 \\
Shi, 2013 [19] & 1 & 1 & 1 & 1 & 1 & 1 & 1 \\
\hline
\end{tabular}

with stage I-IV DLBCL and the other 2 included patients with stage III-IV DLBCL. All studies tested the use of RT after CR to 6-8 cycles of rituximab combined with anthracycline-based chemotherapy. CHOP treatment was the preferred regimen in these studies. Upon completion of chemotherapy, consolidative involved-field RT (IFRT) was allowed, at the treating physician's discretion. In all of the studies, it was not specified how RT was to be used. It is assumed that IFRT was more likely to be given to patients who had previously had bulky disease.

\section{Quality Assessment}

The quality assessment for the included studies is described in table 2. Out of a maximum 9-point score, 2 studies had quality scores of 7 and 2 had a score of 8 . All studies had an appropriate cohort selection, including the representativeness of the RT cohort and the selection of the no-RT cohort. All studies ascertained RT exposure and DLBCL outcomes via the medical records.

\section{Association of $R T$ and $O S$}

Four studies comprising 633 patients with stage I-IV DLBCL were analyzed for OS [16-19]. The addition of RT showed an improvement in OS in all patients (RT vs. no-
RT: $\mathrm{HR}=0.33,95 \% \mathrm{CI} 0.14-0.77, \mathrm{p}=0.01$; fig. 2 ), with no heterogeneity among studies $\left(\mathrm{p}=0.73, \mathrm{I}^{2}=0 \%\right)$. Moreover, no publication bias was detected with a $\mathrm{p}$ value of 0.438 in Egger's test and no significant outcome of influence analysis was observed.

Two studies comprising 189 patients with stage III-IV DLBCL were analyzed for OS $[18,19]$. The RT arm had a trend of improving the OS, but no significant difference (RT vs. no-RT: $\mathrm{HR}=0.35,95 \%$ CI $0.12-1.05, \mathrm{p}=0.06$; fig. 3$)$, with no heterogeneity among studies $(\mathrm{p}=0.39$, $\left.\mathrm{I}^{2}=0 \%\right)$.

\section{Association of RT and PFS/EFS}

Two studies comprising 401 patients with stage I-IV DLBCL were analyzed for PFS $[16,19]$. The addition of RT showed no improvement in PFS in all patients (RT vs. no-RT: $H R=0.24,95 \%$ CI $0.05-1.24, \mathrm{p}=0.09$ ), with no heterogeneity among studies $\left(\mathrm{p}=0.22, \mathrm{I}^{2}=32 \%\right)$.

Two studies comprising 232 patients with stage I-IV DLBCL were analyzed for EFS $[17,18]$. The RT arm was associated with a significant decrease of hazard for EFS in all patients (RT vs. no-RT: $\mathrm{HR}=0.24,95 \%$ CI $0.1-0.57$, $\mathrm{p}=0.001)$, with no heterogeneity among studies $(\mathrm{p}=0.97$, $\left.\mathrm{I}^{2}=0 \%\right)$. 


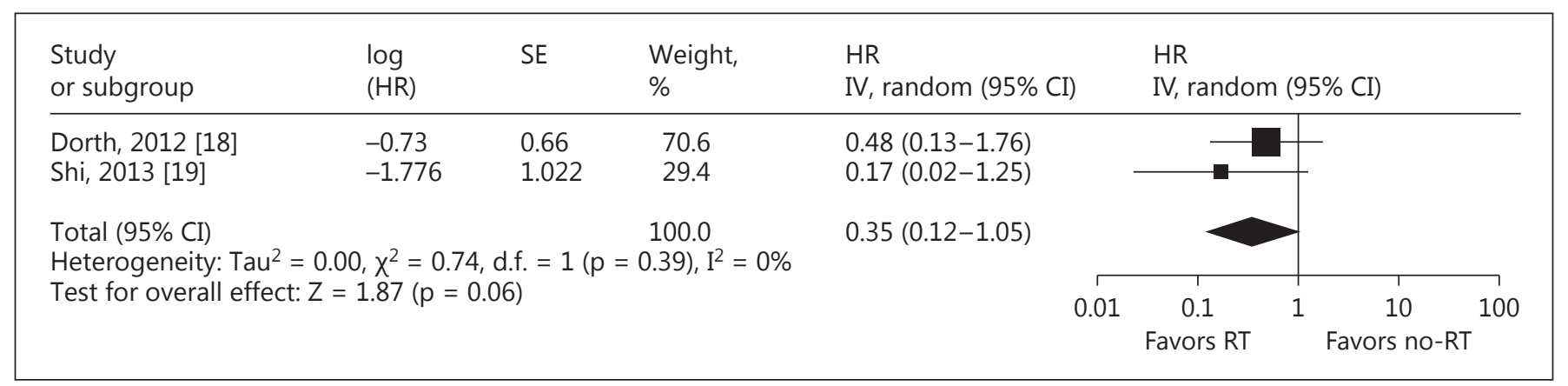

Fig. 3. Forest plot of OS for patients with stage III-IV DLBCL.

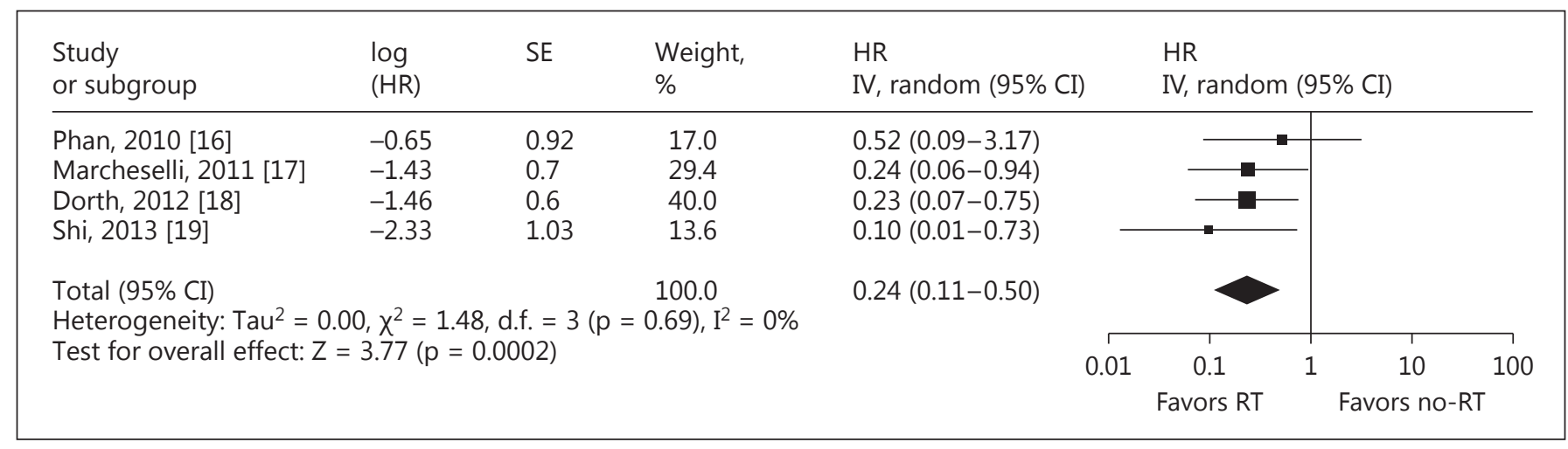

Fig. 4. Forest plot of PFS/EFS for all the patients.

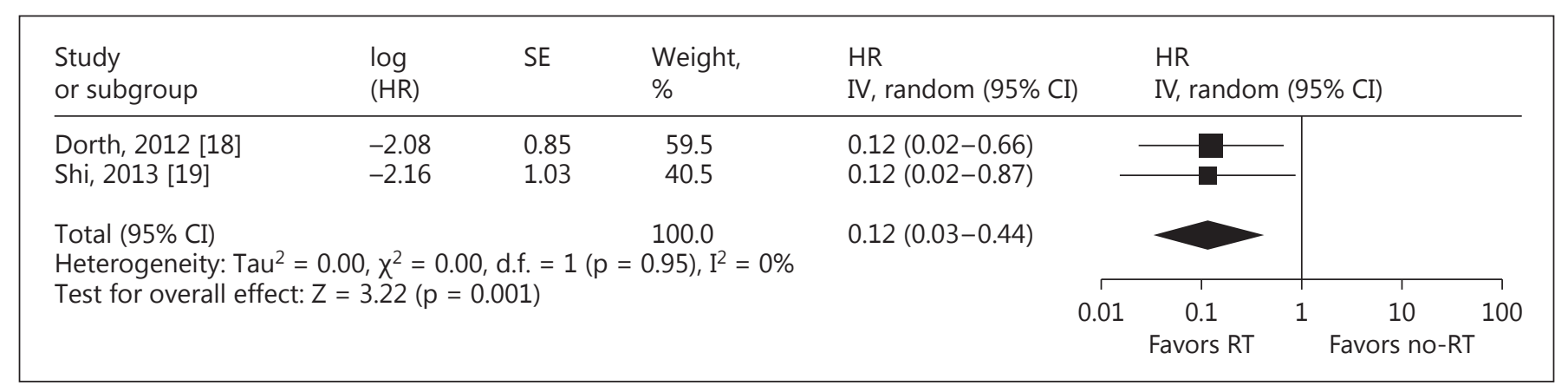

Fig. 5. Forest plot of LC for patients with stage III-IV DLBCL.

Four studies comprising 633 patients with stage I-IV DLBCL were analyzed for PFS/EFS [16-19]. The RT arm was associated with a significant decrease of hazard for $\mathrm{PFS} / \mathrm{EFS}$ in all patients (RT vs. no-RT: $\mathrm{HR}=0.24,95 \%$ CI $0.11-0.5, \mathrm{p}=0.0002$; fig. 4 ), with no heterogeneity among studies $\left(\mathrm{p}=0.69, \mathrm{I}^{2}=0 \%\right)$. Moreover, no publica- tion bias was detected with a p value of 0.542 in Egger's test and no significant outcome of influence analysis was observed.

Two studies comprising 189 patients with stage III-IV DLBCL were analyzed for PFS/EFS [18, 19]. The RT arm was associated with a significant decrease of hazard for 
PFS/EFS in patients with stage III-IV DLBCL (HR = $0.19,95 \%$ CI $0.07-0.51, p=0.001$ ), with no heterogeneity among studies $\left(\mathrm{p}=0.47, \mathrm{I}^{2}=0 \%\right)$.

\section{Association of $R T$ and $L C$}

Two studies comprising 189 patients with stage III-IV DLBCL were analyzed for LC $[18,19]$. The RT arm was associated with significantly improved LC in patients with stage III-IV DLBCL (HR $=0.12$, 95\% CI 0.03-0.44, $\mathrm{p}=0.001$; fig. 5 ), with no heterogeneity among studies $\left(\mathrm{p}=0.95, \mathrm{I}^{2}=0 \%\right)$.

A sensitivity analysis was performed by excluding each study individually in order to evaluate the stability of the results. The statistical significance of the results was not altered when any one study was omitted; this confirmed the stability of the results.

\section{Discussion}

The role of consolidation RT in DLBCL is very controversial. Four randomized trials have been conducted to evaluate this role in patients with early-stage DLBCL: the Southwest Oncology Group (SWOG) 8736 trial [20, 21], the Groupe d'Etude des Lymphomes de l'Adulte (GELA) LNH 93-1 trial [22], the Eastern Cooperative Oncology Group (ECOG) 1484 trial [2], and the GELA LNH 93-4 trial [6]. Unfortunately, these trials were unable to conclusively determine the benefit of RT for patients with stage I-II DLBCL. It was suggested that RT could improve LC, and possibly PFS and OS. For patients with advanced-stage DLBCL, 2 randomized trials, both performed by the same group in Mexico, showed that the addition of RT improved both PFS and OS in patients who achieved a CR after CHOP-like chemotherapy $[3,4]$.

The above studies were all conducted in the era before anti-CD20 treatment. More recently, rituximab has been incorporated into the treatment of patients with DLBCL, with clear benefits in PFS and OS [7, 9, 23], and the question of additive RT is of renewed interest. The results of the phase II SWOG 0014 trial that integrated rituximab into 3 cycles of CHOP plus IFRT in the treatment of limited-stage DLBCL are encouraging [24]. Compared with SWOG 8736, this trial resulted in improved 4-year PFS ( 88 vs. $78 \%$ ) and OS (92 vs. $88 \%$ ). To address the role of $\mathrm{RT}$ in elderly patients with CD20-positive aggressive Bcell lymphoma who received RCHOP, an amendment to the RICOVER-60 trial conducted by the German High-Grade Non-Hodgkin Lymphoma Study Group (DSHNHL) was implemented $[25,26]$. In this amend- ment, a cohort of patients, designated as RICOVERnoRTh treated with RCHOP, but not RT, was compared with patients who had received the same immunochemotherapy plus RT for bulky disease and extralymphatic involvements in the randomization phase of the same trial. Patients with DLBCL accounted for $80 \%$. In the 2008 meeting of the ASH, the trial with a median observation time of 17 months revealed that there were no significant differences between the RT and no-RT cohorts in EFS, PFS and OS, but that in the subgroup analysis of patients with bulky disease, RT was associated with an improved EFS but no difference in PFS and OS [25]. By analyzing these data, it was suggested that, in the rituximab era, additional radiotherapy to bulky disease had no effect in elderly patients with a CR/unconfirmed CR after the completion of RCHOP immunochemotherapy. However, after a median observation time of 39 months, this trial demonstrated a similar outcome in both cohorts with respect to EFS, PFS and OS, but that RT was beneficial to patients with bulky disease [26]. The question about whether the administration of RT is indeed beneficial to patients with a CR after immunochemotherapy remains unanswered.

Up to now, there is no standard follow-up treatment for DLBCL patients who achieve CR after RCHOP. Studies were performed to evaluate the role of $\mathrm{RT}$ in such patients. A retrospective study from the MD Anderson Cancer Center, Houston, Tex., USA, evaluated 291 patients with both localized and advanced-stage DLBCL who received 6-8 cycles of RCHOP and achieved a documented CR [16]. The results showed that RT improved both PFS and OS. Another study from Italy on 153 patients who obtained CR after RCHOP suggested that IFRT treatment yielded a significant EFS benefit whereas the effect of IFRT on OS was moderate and not statistically significant [17]. Data from a study on 79 patients with stage III-IV DLBCL who achieved a CR to chemotherapy (RCHOP), i.e. $65 \%$, showed that RT was associated with improved LC and EFS, but not with OS [18]. A recently published retrospective study addressed the role of consolidative RT in patients with stage III-IV DLBCL who had CR after being treated with RCHOP [19]. It suggested that incorporation of consolidative RT for these patients was associated with improved LC and PFS as well as a trend towards improved OS. The importance of the results from the above 4 studies is limited because conclusive data from conflicting studies about the impact of RT are lacking.

These studies were included in a meta-analysis. The results showed that RT enhanced OS, PFS/EFS and EFS 
for all DLBCL patients who achieved CR after RCHOP, regardless of disease stage. In addition, RT improved LC and PFS/EFS for patients with stage III-IV DLBCL, but there was no impact on OS. There was no heterogeneity among studies. However, this meta-analysis had its limitations: (1) The 4 studies included were retrospective and nonrandomized trials, so there could be an uncontrollable selection bias; (2) IFRT was performed at the treating physician's discretion, without a unified standard. Further investigations are needed to clarify the role of RT in the rituximab era.

More recently, the International Lymphoma Radiation Oncology Group has developed some guidelines on the use of RT in NHL in the modern era [27]. The guidelines claim that RT continues to have an important role in increasing local regional control in combined treatment programs for many early-stage presentations, as well as for selected bulky, extranodal, advanced-stage, aggressive NHL presentations, even though immunochemotherapy with the addition of rituximab has evolved with increasing efficacy for the management of many Bcell NHLs. The guidelines also recommend involved-site RT to replace extended-field and involved-field RT techniques; this is a new concept to define the clinical target volume. When patients with advanced-stage disease achieve a CR after chemotherapy, consolidation involvedsite RT is used. Because the gross tumor volume may be markedly affected by systemic chemotherapy, it is particularly important to review the prechemotherapy imaging and outline the prechemotherapy volume as 'prechemotherapy gross tumor volume'.

The UNFOLDER (Unfavorable Low-Risk Patients Treated with Densification of R-Chemo Regimens) trial, a German phase 3, prospective, randomized trial, is still being conducted by the DHSNHL group. It compares 2 schedules of RCHOP (RCHOP-21 or-14) with or without consolidative RT in aggressive B-cell NHL patients [28]. Relatively young patients (aged 18-60 years), initially with bulky disease $(\geq 7.5 \mathrm{~cm})$ and/or qualifying extranodal involvement, who achieved CR to 6 cycles of RCHOP-14 or - 21 will be further randomized to observation versus consolidative RT. The interim analysis disclosed at the International Lymphoma Study Group at the ASTRO 2012 meeting revealed that patients in the consolidative RT arm had superior OS compared to those who received RCHOP alone. Thus, the immunochemotherapy-alone arms were prematurely closed, while the $\mathrm{RCHOP}$ plus RT arms continue to accrue. It was also suggested that additive RT was of great benefit to subpopulations with DLBCL in the rituximab era (ClinicalTrials. gov identifier, NCT00278408). Unfortunately, the data of this particular study were not published, so it could not be included in this meta-analysis. We await additional results from this landmark study to help shed light on the role of consolidative RT.

With advances in medicine, there are still many unanswered questions regarding the effects of RT in patients with DLBCL. It is unclear how to incorporate PET-assessed response into a treatment algorithm for DLBCL, and whether or not PET scans could successfully define a subset of patients who do not benefit from radiation. Investigation is needed as to whether a longer or more intensive course of rituximab-containing chemotherapy without RT is equivalent or even superior to RCHOP combined with RT.

\section{Conclusion}

Our study strongly supported the hypothesis that RT has a clinically useful role in the rituximab era. It should be considered as an option for DLBCL patients who achieve a CR to RCHOP, especially those with bulky disease. Our conclusions were limited by the retrospective nature of the data. Future prospective studies with a larger sample size are required to confirm our findings.

\section{Disclosure Statement}

There are no actual or potential conflicts of interest from the authors.

\section{References}

Acta Haematol 2015;134:111-118

1 Clarke C: Non-Hodgkin lymphoma. www. seer.cancer.gov/publications/survival/surv_ nonhodgkin, National Cancer Institute, 2011.

2 Horning SJ, Weller E, Kim K, Earle JD, O'Connell MJ, Habermann TM, Glick JH: Chemotherapy with or without radiotherapy in limited-stage diffuse aggressive non-Hodgkin's lymphoma: Eastern Cooperative Oncology Group Study 1484. J Clin Oncol 2004;22: 3032-3038.

3 Aviles A, Fernandezb R, Perez F, Nambo MJ, Neri N, Talavera A, Castaneda C, Gonzalez $\mathrm{M}$, Cleto S: Adjuvant radiotherapy in stage IV diffuse large cell lymphoma improves outcome. Leuk Lymphoma 2004;45:1385-1389.

4 Aviles A, Delgado S, Nambo MJ, Alatriste S, Diaz-Maqueo JC: Adjuvant radiotherapy to sites of previous bulky disease in patients stage IV diffuse large cell lymphoma. Int J Radiat Oncol Biol Phys 1994;30:799-803. 
5 Bonnet C, Fillet G, Mounier N, Ganem G, Molina TJ, Thieblemont C, Ferme C, Quesnel B, Martin C, Gisselbrecht C, Tilly H, Reyes F: $\mathrm{CHOP}$ alone compared with $\mathrm{CHOP}$ plus radiotherapy for localized aggressive lymphoma in elderly patients: a study by the Groupe d'Etude des Lymphomes de l'Adulte. J Clin Oncol 2007;25:787-792.

6 Feugier P, Van Hoof A, Sebban C, Solal-Celigny P, Bouabdallah R, Fermé C, Christian B, Lepage E, Tilly H, Morschhauser F, Gaulard P, Salles G, Bosly A, Gisselbrecht C, Reyes F, Coiffier B: Long-term results of the R-CHOP study in the treatment of elderly patients with diffuse large B-cell lymphoma: a study by the Groupe d'Etude des Lymphomes de l'Adulte. J Clin Oncol 2005;23:4117-4126.

7 Pfreundschuh M, Trumper L, Osterborg A, Pettengell R, Trneny M, Imrie K, Ma D, Gill D, Walewski J, Zinzani PL, Stahel R, Kvaloy S, Shpilberg O, Jaeger U, Hansen M, Lehtinen T, Lopez-Guillermo A, Corrado C, Scheliga A, Milpied N, Mendila M, Rashford M, Kuhnt E, Loeffler M: CHOP-like chemotherapy plus rituximab versus $\mathrm{CHOP}$-like chemotherapy alone in young patients with good-prognosis diffuse large-B-cell lymphoma: a randomised controlled trial by the MabThera International Trial (MInT) group. Lancet Oncol 2006;7: 379-391.

8 Coiffier B, Thieblemont C, Van Den Neste E, Lepeu G, Plantier I, Castaigne S, Lefort S, Marit G, Macro M, Sebban C, Belhadj K, Bordessoule D, Ferme C, Tilly H: Long-term outcome of patients in the LNH-98.5 trial, the first randomized study comparing rituximabCHOP to standard CHOP chemotherapy in DLBCL patients: a study by the Groupe d'Etudes des Lymphomes de l'Adulte. Blood 2010;116:2040-2045.

9 Pfreundschuh M, Kuhnt E, Trumper L, Osterborg A, Trneny M, Shepherd L, Gill DS, Walewski J, Pettengell R, Jaeger U, Zinzani PL, Shpilberg O, Kvaloy S, de Nully Brown P, Stahel R, Milpied N, Lopez-Guillermo A, Poeschel V, Grass S, Loeffler M, Murawski N: CHOP-like chemotherapy with or without rituximab in young patients with good-prognosis diffuse large-B-cell lymphoma: 6-year results of an open-label randomised study of the MabThera International Trial (MInT) group. Lancet Oncol 2011;12:1013-1022.

10 The Newcastle-Ottawa Scale (NOS) for assessing the quality of nonrandomised studies in meta-analyses. 3rd Symposium on Systematic Reviews: Beyond the Basics 2002. http:// www.ohri.ca/programs/clinical_epidemiology/oxford.asp.

11 Parmar MK, Torri V, Stewart L: Extracting summary statistics to perform meta-analyses of the published literature for survival endpoints. Stat Med 1998;17:2815-2834.

12 Tierney JF, Stewart LA, Ghersi D, Burdett S, Sydes MR: Practical methods for incorporating summary time-to-event data into metaanalysis. Trials 2007;8:16.

13 DerSimonian R, Laird N: Meta-analysis in clinical trials. Controlled clinical trials 1986;7: 177-188.

14 Higgins JP, Thompson SG, Deeks JJ, Altman DG: Measuring inconsistency in meta-analyses. BMJ 2003;327:557-560.

15 Egger M, Davey Smith G, Schneider M, Minder C: Bias in meta-analysis detected by a simple, graphical test. BMJ 1997;315:629-634.

16 Phan J, Mazloom A, Medeiros LJ, Zreik TG, Wogan C, Shihadeh F, Rodriguez MA, Fayad L, Fowler N, Reed V, Horace P, Dabaja BS: Benefit of consolidative radiation therapy in patients with diffuse large B-cell lymphoma treated with R-CHOP chemotherapy. J Clin Oncol 2010;28:4170-4176.

17 Marcheselli L, Marcheselli R, Bari A, Liardo EV, Morabito F, Baldini L, Brugiatelli M, Merli F, Di Renzo N, Sacchi S: Radiation therapy improves treatment outcome in patients with diffuse large B-cell lymphoma. Leuk Lymphoma 2011;52:1867-1872.

18 Dorth JA, Prosnitz LR, Broadwater G, Diehl LF, Beaven AW, Coleman RE, Kelsey CR: Impact of consolidation radiation therapy in stage III-IV diffuse large B-cell lymphoma with negative post-chemotherapy radiologic imaging. Int J Radiat Oncol Biol Phys 2012;84: 762-767.

19 Shi Z, Das S, Okwan-Duodu D, Esiashvili N, Flowers C, Chen Z, Wang X, Jiang K, Nastoupil LJ, Khan MK: Patterns of failure in advanced stage diffuse large B-cell lymphoma patients after complete response to $\mathrm{R}-\mathrm{CHOP}$ immunochemotherapy and the emerging role of consolidative radiation therapy. Int J Radiat Oncol Biol Phys 2013;86:569-577.

20 Miller TP, Dahlberg S, Cassady JR, Adelstein DJ, Spier CM, Grogan TM, LeBlanc M, Carlin S, Chase E, Fisher RI: Chemotherapy alone compared with chemotherapy plus radiotherapy for localized intermediate- and highgrade non-Hodgkin's lymphoma. N Engl J Med 1998;339:21-26.

21 Miller TP, Leblanc M, Spier CM, Chase E, Fischer RI: CHOP alone compared to CHOP plus radiotherapy for early stage aggressive non-Hodgkin's lymphomas: update of the Southwest Oncology Group (SWOG) randomized trial. Blood 2001;98:742a-743a.

22 Reyes F, Lepage E, Ganem G, Molina TJ, Brice P, Coiffier B, Morel P, Ferme C, Bosly A, Lederlin P, Laurent G, Tilly H; Groupe d'Etude des Lymphomes del'Adulte: ACVBP versus $\mathrm{CHOP}$ plus radiotherapy for localized aggressive lymphoma. N Engl J Med 2005;352:1197-1205.

23 Vose JM, Link BK, Grossbard ML, Czuczman M, Grillo-Lopez A, Gilman P, Lowe A, Kunkel LA, Fisher RI: Phase II study of rituximab in combination with CHOP chemotherapy in patients with previously untreated, aggressive non-Hodgkin's lymphoma. J Clin Oncol 2001;19:389-397.

24 Persky DO, Unger JM, Spier CM, Stea B, LeBlanc M, McCarty MJ, Rimsza LM, Fisher RI, Miller TP: Phase II study of rituximab plus three cycles of CHOP and involved-field radiotherapy for patients with limited-stage aggressive B-cell lymphoma: Southwest Oncology Group Study 0014. J Clin Oncol 2008;26: 2258-2263.

25 Pfreundschuh M, Ziepert M, Reiser M, Poeschel V, Wilhelm S, Gaska T, Heike M, Schmitz N, Ruebe C, Loeffler M, Schubert J: The role of radiotherapy to bulky disease in the rituximab era: results from two prospective trials of the German High-Grade Non-Hodgkin-Lymphoma Study Group (DSHNHL) for elderly patients with DLBCL. 50th Annual Meeting of the American Society of Hematology, Moscone Center, San Francisco, 2008

26 Held G, Murawski N, Ziepert M, Fleckenstein J, Poschel V, Zwick C, Bittenbring J, Hanel M, Wilhelm S, Schubert J, Schmitz N, Loffler M, Rube C, Pfreundschuh M: Role of radiotherapy to bulky disease in elderly patients with aggressive B-cell lymphoma. J Clin Oncol 2014;32:1112-1118.

27 Illidge T, Specht L, Yahalom J, Aleman B, Berthelsen AK, Constine L, Dabaja B, Dharmarajan K, Ng A, Ricardi U, Wirth A: Modern radiation therapy for nodal non-Hodgkin lymphoma - target definition and dose guidelines from the International Lymphoma Radiation Oncology Group. Int J Radiat Oncol Biol Phys 2014;89:49-58.

28 Shi Z, Esiashvili N, Flowers C, Das S, Khan MK: Renewed interest in the role of consolidative radiotherapy in advanced stage diffuse large B-cell lymphoma. Leuk Lymphoma 2013;54:2122-2130. 